\title{
Kebijakan Tata Kelola Otoritas Jasa Keuangan (OJK) Di Indonesia
}

\author{
Nabilah Farah Diba ${ }^{1}$ *, Hari Sutra Disemadi ${ }^{2}$, Paramita Prananingtyas ${ }^{3}$ \\ ${ }^{1}$ Fakultas Hukum, Universitas Diponegoro, Kampus Pleburan, Semarang, Indonesia \\ * Korespondensi Penulis. E-mail: dibanabilah@gmail.com
}

\begin{abstract}
Abstrak
Banyaknya masalah lintas sektoral di sektor jasa keuangan, seperti ukuran risiko etika, perlindungan yang memadai terhadap konsumen jasa keuangan, dan stabilitas keuangan sektor jasa keuangan, membuat otoritas pengawasan sektor jasa keuangan semakin dibutuhkan. Maka dari itu, penelitian ini bertujuan untuk menggambarkan kabijakan pengaturan hadirnya Otoritas Jasa Keuangan (OJK) yang memiliki fungsi pengaturan serta pengawasan terhdap jasa keuangan, kemudian penelitian ini bertujuan untuk menggambarkan kebijakan tata kelola kerja OJK di Indonesia. Metode yang digunakan pada penelitian ini adalah metode penelitian hukum normative dengan pendekatan konseptual serta pendekatan perundang-undangan. Penelitian ini menunjukan hadirnya OJK merupakan salah satu kebutuhan Indonesia dalamhal pembentukan regulator untuk sektor jasa keuangan, termasuk bank, perusahaan asuransi, dana pensiun, sekuritas, modal ventura dan perusahaan pembiayaan, dan perusahaan publik lainnya serta pengawasannya. Dasar hukum penyelenggaraan OJK adalah UndangUndang Nomor 21 Tahun 2011 tentang Otoritas Jasa Keuangan yang diundangkan pada tanggal 22 November 2011. OJK sebagai lembaga sektor publik, dalam tata kelolanya harus menerapkan Good Corporate Governance (GCG) yang merupakan komponen mendasar dari kemampuan OJK untuk menjalankan fungsinya dalam jangka panjang. GCG adalah ukuran kinerja OJK, yang mencakup 4 bagian yaitu Governanve Principles, Governance Structure, Governance Process, dan Governance Outcome. Kemudain Governanve Principles transparansi, akuntabilitas, tanggung jawab, kemandirian, dan kesetaraan atau kewajaran.
\end{abstract}

Kata Kunci: Kebijakan, Tata Kelola, Otoritas Jasa Keuangan

\section{Financial Services Authority (FSA) Governance Policy in Indonesia}

\begin{abstract}
A large number of cross-cutting issues in the financial services sector, such as measures of ethical risk, adequate protection of consumers of financial services, and financial stability of the financial services sector, make financial service sector oversight authorities increasingly needed. Therefore, this study aims to describe the regulatory arrangements for the presence of the Financial Services Authority (FSA) which has a regulatory and supervisory function for financial services, then this study aims to describe the FSA's work governance policies in Indonesia. The method used in this study is a normative legal research method with a conceptual approach and legislation approach. This study shows the presence of FSA is one of Indonesia's needs in terms of the formation of regulators for the financial services sector, including banks, insurance companies, pension funds, securities, venture capital and finance companies, and other public companies and their supervision. The legal basis for the implementation of the FSA is Law Number 21 of 2011 concerning the Financial Services Authority which was promulgated on November 22, 2011. FSA as a public sector institution must implement Good Corporate Governance (GCG) which is a fundamental component of FSA's ability to run its function in the long run. GCG is a measure of OJK's performance, which includes 4 parts namely Governance Principles, Governance Structure, Governance Process, and Governance Outcome. Then the Governance Principles are transparency, accountability, responsibility, independence, and fairness.
\end{abstract}

Keywords: Policy, Governance, Financial Services Authority 
EKSPOSE: Jurnal Penelitian Hukum dan Pendidikan, 18 (2), Desember 2019 - 869

Nabilah Farah Diba, Hari Sutra Disemadi, Paramita Prananingtyas

\section{PENDAHULUAN}

Perekonomian nasional dewasa ini telah berkembang begitu pesat dan telah menghasilkan bemacam-macam jenis barang dan atau jasa. Perkembangan sistem perekonomian di Indonesia ini tidak luput dengan dengan adanya perkembangan teknologi dan informasi pula. ${ }^{1}$ Perkembangan perekonomian dewasa ini menuntut penyedia jasa keuangan seperti lembaga keuangan perbankan dan lembaga keuangan lainnya agar selalu berinovasi dan mengembangkan produk jasa keuangan yang mereka sediakan. ${ }^{2}$ Berkembang pesatnya lembanga keuangan di Indonesia mengharuskan hadirnya otoritas yang melakukan fungsi pengaturan serta pengawasan terhadap lembaga keuangan tersebut. Di Indonesia otoritas yang memiliki fungsi pengaturan serta pengawasan terhadap lembaga keuangan adalah OJK atau Otoritas Jasa Keuangan. ${ }^{3}$

Sistem baru pengaturan dan pengawasan sektor jasa keuangan di Indonesia dimulai saat disahkannya peraturan tentang OJK. ${ }^{4} \mathrm{OJK}$ sebagai lembaga baru dalam pengaturan dan pengawasan jasa keuangan di amanatkan untuk dibentuk paling lambat 22 Juli 2012 oleh Undang-Undang Nomor 21 Tahun 2011 tentang Otoritas Jasa Keuangan. OJK sebagai lembaga yang independen wajib menumbuhkan kepercayaan dan hubungan baik dengan lembaga pemberi jasa keuangan, masyarakat, pemerintah yang merupakan wujud ikatan sosial. ${ }^{5}$ Semakin luasnya perkembangan lembaga keuangan di Indonesia, maka untuk meningkatkan kepercayaan publik menyebabkan fungsi OJK harus diimplementasikan secara optimal, agar tidak mengahdirkan risiko yang tidak diinginkan. Untuk itu perlu adanya kebijakan yang berkaitan dengan tata kelola OJK yang baik. ${ }^{6}$

Pengoperasian OJK tidak dapat dilepaskan dengan tuntutan pelaksanaan tata kelola lembaga atau perusahaan yang baik (Good Corporate Governance atau GCG) (Melia, 2015). Tuntutan ini diakibatkan banyaknya jasa keuangan yang tanpa izin beroperasi. Terutama jasa keuangan yang mengandalkan teknologi dan informsi seperti fintech lending. Bedasarkan siaran pers OJK (SP 06/IX/SWI/2019), Satgas Waspada Investasi (SWI) dalam penindakannya kembali menemukan 123 fintech lending ilegal dan 30 usaha gadai yang tidak terdaftar di OJK serta 49 entitas penawaran investasi yang tidak berizin. Permasalahan terkait jasa keuangan ini mengharuskan OJK untuk meningkatkan tata kelola lembaga yang baik sehingga mampu menjalankan fungsinya dalam pengaturan serta pengawasan jasa keuangan di Indonesia.

Good Corporate Governance (GCG) merupakan sebuah sistem nilai yang menjadi tolak ukur kemampuan sebuah perusahaan dalam menjalankan aktivitas operasional dan proses kegiatan fungsinya secara sehat. Struktur organ GCG, kepatuhan terhadap peraturan dan perundang-undangan yang berlaku, hingga keterbukaan informasi menjadi beberapa aspek GCG yang penting dan mencerminkan pengelolaan organisasi sebuah perusahaan (www.nusantarainfrastructure.com, Diakses 1 November 2019). Bagi perusahaan yang telah berstatus publik atau perusahaan terbuka, GCG diberlakukan sebagai aspek fundamental kemampuan perusahaan untuk melakukan aktivitas usahanya secara jangka panjang. GCG dalam penyelenggaraan OJK telah menjadi salah satu satuan ukuran kemampuan kinerja sebuah perusahaan, selain tentunya kinerja keuangan dan kinerja operasional usaha.

Berdasarkan "uraian latar belakang yang dikemukakan diatas, dapat dirumuskan permasalahan dalam penelitian ini adalah: 1). Bagaimana kebijakan pengaturan Otoritas Jasa Keuangan di Indonesia?; dan 2). Bagaimana kebijakan tata kelola Otoritas Jasa Keuangan di Indonesia?

${ }^{1}$ Hari Sutra Disemadi and Paramita Prananingtyas, "Perlindungan Hukum Terhadap Nasabah Perbankan Pengguna CRM (Cash Recycling Machine)," Jurnal Magister Hukum Udayana (Udayana Master Law Journal) 8, no. 3 (2019): 286-402.

${ }^{2}$ Hari Sutra Disemadi and Raden Ani Eko Wahyuni, "Eksistensi Dan Kebijakan Regulasi Perizinan Lembaga Keuangan Mikro Oleh Otoritas Jasa Keuangan,” Jurnal Yustisiabel 3, no. 2 (2019): 106-17.

3 Zulfi Diane Zaini, "Hubungan Hukum Bank Indonesia Sebagai Bank Sentral Dengan Otoritas Jasa Keuangan (OJK) Pasca Pengalihan Fungsi Pengawasan Perbankan,” Media Hukum 20, no. 2 (2015).

${ }^{4}$ HestyD Lestari, “Otoritas Jasa Keuangan: Sistem Baru Dalam Pengaturan Dan Pengawasan Sektor Jasa Keuangan,” Jurnal Dinamika Hukum 12, no. 3 (2012): 557-67.

${ }^{5}$ Shinta Puspita Sari, "Pembentukan Pengaturan Tentang Good Corporate Governance (Gcg) Pada Bank Pembiayaan Rakyat Syariah," Legal Spirit 2, no. 1 (2018).

${ }^{6}$ Inosentius Samsul, "Perlindungan Konsumen Jasa Keuangan Pasca Pembentukan Otoritas Jasa Keuangan (OJK)," Negara Hukum: Membangun Hukum Untuk Keadilan Dan Kesejahteraan 4, no. 2 (2016): 153-66. 


\section{METODE}

Penelitian ini menggunakan metode penelitian doctrinal atau penelitian hukum normatif. Metode ini menggunakan pendekatan perundang-undangan serta pendekatan konseptual yang mengedepankan bahan hukum primer, sekudender, dan tersier. ${ }^{7}$ Adapun bahan hukum tersebut berupa Undang-Undang Nomor 21 Tahun 2011 tentang Otoritas Jasa Keuangan, literatur buku, dan jurnal penelitian hukum lainnya. Bahan-bahan hukum ini dikumpulkan dengan teknik studi kepustakaan yang kemudian dianalisis dengan tujuan untuk mengarahkan dan mencari serta menemukan kebenaran ilmiah yang sifatnya teroerinci dan dapat dipertanggungjwabkan secara ilmiah dan tidak menyimpang.

\section{HASIL DAN PEMBAHASAN}

\section{Kebijakan Pengaturan Otoritas Jasa Keuangan Di Indonesia}

Untuk mencapai ekonomi yang berkelanjutan, untuk menciptakan peluang kerja yang luas dan seimbang di semua sektor ekonomi dan untuk memastikan kesejahteraan yang adil bagi semua orang Indonesia, program pembangunan nasional harus sepenuhnya diimplementasikan dan mampu memajukan kegiatan ekonomi yang lebih luas, dan menyentuh semua sektor riil ekonomi Indonesia. ${ }^{8}$ Programm Pembangunan Nasional juga harus dilaksannakan secara transparaan dan bertanggung jawab dan sesuai dengan prinsip-prinsip demokrasi ekonomi yang diabadikan dalam Pancasila dan UUD Negara Republik Indonesia Tahun 1945. Dalam mencapaai tujuan-tujuan ini, Program Pengembangan Ekonomi Nasional harus didukung oleh tata pemerintahan yang baik, yang secara terus-menerus memperbaiki semua aspek sistem ekonomi nasional. ${ }^{9}$ Komponen penting dari ekonomi nasional adalah sistem keuangan dan semua kegiatan jasa keuangan yang bertindak sebagai perantara berbagai aktivitas produktif dalam perekonomiian.

Fungsi intermediasi dapat dilakukan oleh berbagai organisasi atau lembaga jasa keuangan telah memberikan kontribusi yang signifikan untuk membiayai pembangunan ekonomi. Karena itu, negara selalu serius mengembangkan kegiatan jasa keuangan, berusaha menciptakan kerangka kerja hukum yang komprehensif dan komprehensif serta pengawasan sektor jasa keuangan. ${ }^{10}$ Globaliisasi dalam sistem keeuangan dan keemajuan pesat dalam teknologii informasi dan inovasii keuangan telahh menciiptakan sisten keuanngan yang sanngat kompleks, diinamis dan saliing terkait antara sub-sektor keuangan dalam hal produk dan institusi. ${ }^{11}$ Selain itu, kebeeradaan lembaga jasa keeuangan yang mempertahankan hubungan kepemiliikan diberbagai sub-sektor keuangan (korporasi) telah meningkatkan kompleksiitas transaksii dan inteeraksi antara lembaga jasa keuangan dalam sisstem keuangan.

Banyaknya masalah lintas sektoral di sektor jasa keuangan, seperti ukuran risiko etika, perlindungan yang memadai terhadap konsumen jasa keuangan, dan stabilitas keuangan sektor jasa keuangan, membuat otoritas pengawasan sektor jasa keuangan semakin dibutuhkan. Terhadap latar belakang ini, perlu untuk merestrukturisasi struktur kelembagaan perusahaan yang melakukan fungsi pengaturran dan pegawasan di seektor jasa keuangan, termasuk sktor perbankan, pasarr modal, asuransi, dana pensiun, lembagga keuangan dan perusahaan jasa keuangan laainnya. Struktur ini dilakukan untuk mencapai mekanissme koordinaasi yang lebih efektif untuk menyelesaikan masalah dalam sistem

${ }^{7}$ Taufani G Suteki, Metodologi Penelitian Hukum (Filsafat, Teori Dan Praktik), PT RajaGrafinfo Persada (Depok, 2018).

${ }^{8}$ Rebekka Dosma Sinaga, Bismar Nasution, and Mahmul Siregar, "Sistem Koordinasi Antara Bank Indonesia Dan Otoritas Jasa Keuangan Dalam Pengawasan Bank Setelah Lahirnya Undang-Undang Nomor 21 Tahun 2011 Tentang Otoritas Jasa Keuangan," TRANSPARENCY 1, no. 2 (2013).

${ }^{9}$ Hari Sutra Disemadi and Kholis Roisah, "Kebijakan Model Bisnis Bank Wakaf Mikro Sebagai Solusi Pemberdayaan Ekonomi Masyarakat," LAW REFORM 15, no. 2 (n.d.): 177-94.

10 Hari Sutra Disemadi, "Risk Management In The Provision Of People's Business Credit As Implementation Of Prudential Principles," Diponegoro Law Review 4, no. 2 (2019): 194-208.

${ }^{11}$ Disemadi and Wahyuni, "Eksistensi Dan Kebijakan Regulasi Perizinan Lembaga Keuangan Mikro Oleh Otoritas Jasa Keuangan.” 
keuangan untuk memastikan stabilitas sistem keuangan dengan lebih baik. Mengkoordinasikan pemantauan dan pengawasan semua kegiatan jasa keuangan.

Selain pertimbangan di atas, Undang-Undang Nomor 23 Tahun 1999 tentang Bank Indonesia tellah mengalami beberapa kaali perubahan dan mengamanatkan pembentukan regulator untuk sektor jasa keuangan, termasuk bank, perrusahaan asurransi, dana pensiuun, sekurtitas, modal venturra dan perusahaan pembiayaan, dan perusahaan publik lainnya. Otoritas Pengatur Jasa Keuangan sebagaimana dimaksud di atas pada dasarnya adalah badan independen yang melakukan tugaasnya dan posisinya berada di luaar pemerrintah. Lembaga ini wajib melaporkan ke Badan Pemeriksa Keuangan (BPK) dan Dewan Perrwakilan Rakyat (DPR).

Otoritas Jasa Keuangan (OJK) merupakan jawaban atas dasar permasalahan di atas melalui di undangkannya Undang-Undang Nomor 21 Tahun 2011 tentang Otoritas Jasa Keuangan (UU OJK) yang diundangkan pada tanggal 22 November 2011. Pasal 1 angka (1) UU OJK menyebutkan "Otorritas Jasa Keuangan, yang selaanjutnya disingkaat OJK, adalah leembaga yang independeen dan beebas dari campur tangan pihak lain, yang mempunyai fungssi, tugas, dan wwenang pengatuaran, pengawasaan, pemeriksaaan, dan penyiidikan sebagaaimana dimaksud dalam Unndang-Undang ini”.

Setiap lembaga yang diddirikan teentu memiliki visi, misi dan tujuan yaang inngin dicaapai. Visi meerupakan impiaan yang ingin dicaapai oleh suatu leembaga, deengan meneetapkan suatu misi. Seetelah visi dan misi ditetaapkan maka selaanjutnya adaalah menetapkaan tuujuan suuatu lembaga, baik tujuan jangka pendek maupun tujuan jangka panjang. Demikian pula dengan pendirian dan pembentukan OJK. Visi OJK yaitu uuntuk menjaadi lembaga pengaawas industri jaasa keuaangan yang terpercaya, melindungi kepentingan konsumeen dan masyarakat, dan mampu mewujuddkan inddustri jasa keuaangan menjadi pilaar perekonomian nasional yang berdaya saaing global serta dapaat memajukan kesejahteraan umuum (Tentang OJK, www.ojk.go.id, Diakses 01 November 2019). Artiinya cita-cita OJK utamanya adalah meenginginkan jasa keuangan yang dijjalankan olleh lembaga keuangan dapat memberikan dampak positif/mamfaat yang sebesar-besarrnya untuk kepenttingan konsumen dan masyarrakat di Indonesia. ${ }^{12}$ Kemudian Misi yang diemban oleh OJK dalam rangka mencapai Visinya berdasarkan Pasal 4 UU OJK, adalah mewujudkan keseluruhan kegiatan di dalam sektor jasa keuangan: “a). Terselenggara seccara teratur, adil, teransparan, dan akeuntabel; b). Mampu mewujudken sistem keuangen yang tumbuh sacara berkelanjutan dan steabil; dan c). Meampu melindungi kepentingan Konsumen dan masyarrakat".

Di samping memilki visi dan misi, OJK memiliki fungsi, tugas, dan wewenang yang telah di tentukan oleh UU OJK. Pasal 5 UU OJK menyebutkan "OJK berfungsi menyelenggarakan sistem pengaturan dan pengawaasan yang terinttegrasi terhadap kesealuruhan keagiatan di dalam sektor jasa keuangan".

Tugas OJK melaksanakan pengaturran dan pengawassan terhadap kegiatan jassa keuangaan di sektor Perbanken, pasar Modal, asuransi, dana pensiun, lembaga pembiayaan, dan lembaga jasa keuangan lainnya, seperti telah disebutkan pada Pasal 6 UU OJK. Wewenang OJK terbagi atas tugas pengaturan dan tugas pengawasan. ${ }^{13}$ Aapun tugas pengaturan OJK disebutkan pada Pasal 8 UU OJK, yakni sebagai berikut: a). Meneatapkan peraturean pelaksanaan Undaang-Undang OJK; b). Meneatapkan peraturan perrundang-undangan disektor jasa keeuangan; c). Meneetapkan peraturran den keputusann OJK; d). Menetapkan peraturan mengeenai pengawsan di sektor jeasa keuangan; e). Menetapkan kebijakaan mengenai pelaksannaan tugas OJK; f). Mennetapkan perraturan mengeneai tata cara penetappan perinntah tertulis terhadap Lembaga Jasa Keuangan dan pihak tertentu; g). Menetapkan peraturan mengenai tata cera penetapan pengellola statutter pade Lembaga Jasa Keuangan; h). Menetapkan strruktur orrganisasi dan infreastruktur, seerta mengelolla, memeliharaa, dan menatausahaakan kekayaan dan kewajiiban; dan i). Menetapkan peratturan mengenai tata cara pengenaan sannksi sesuai dengan ketenttuan peraturan perundang-perunddangan di seektor jasa keuangan.

Adanya pembentukan OJK, diharapkan OJK dapat mendukung kepentingan sektor keuangan secara menyeluruh sehingga meningkatkan daya saing perekonomian. OJK juga diharapkan mampu mewujudkan sistem keuangan yang tumbuh secara berkelanjutan dan stabil serta OJK diharapkan

${ }^{12}$ Yuliani Yuliani, "Bank Dan Lembaga Keuangan Lainnya" (Citrabooks Indonesia, 2016).

${ }^{13}$ Syamsu Iskandar, "Bank Dan Lembaga Keuangan Lainnya," Jakarta: In Media, 2013. 
mampu melindungi konsumen maupun masyarakat (FAQ Otoritas Jasa Keuangan, www.ojk.go.id Diakses Pada Tanggal 29 Oktober 2019).

\section{Kebijakan Tata Kelola Otoritas Jasa Keuangan Di Indonesia}

UU OJK pada dasarnya berisi ketentuan tentang organnisasi dan tata kelola organisasi (Governace) dengan wewenang pengawasan dan peraturan di sektor jasa keuangan. OJK didirikan dengan tujuan mengelola semua kegieatan jasa keuaengan dalam industri jasa keuangan secara sistematis, adill, transsparan, dan bertanggung jawab dan mampu meweujudkan sisstem keauangan yang berkembang seccara berrkelanjutan, dan mampu melindungi keepentingan konssumen dan masyarakat. Sejalan dengan tujuaan ini, OJK harus dapat mendukkung keppentingan sektor jasa keuangan nasional untuk meningkaatkan daya saaing nasional. Selain itu, dengan mempertimbangkan aspek positif globalisasi, OJK harus mmpu melindungi kepentingan nasional, termasuk sumber daya manusia, manajemen, pengawsan dan kepeemilikan di sektorr jasa keuangan.

Penjelasan UU OJK menyebutkan "Otoritas Jasa Keuangan dibentuk dan dilandasi dengan prinsip-prrinsip tataa kelola yng baik, yang meliputti indeependensi, akuntabillitas, pertangggungjawaban, trannsparansi, dan kewajaran (fairness)". Sistem nilai, juga dikenal sebagai tata kelola perusahaan yang baik (Good Corporate Governance atau GCG), mengukur kemampuan perusahaan untuk melakukan kegiatan operasional dan proses kegiatan fungsinya secara sehat. Pembentukan organisasi GCG dan kepatuhan terhadap hukum dan peraturan yang berlaku, sehingga mengungkapkan informasi tentang beberapa aspek utama GCG dan arahan organisasi perusahaan. ${ }^{14}$

OJK sebagai lembaga sektor publik, GCG adalah komponen mendasar dari kemampuan OJK untuk menjalankan fungsinyanya dalam jangka panjang. ${ }^{15}$ Dengan diterbitkannya peta tata kelola Otoritas Jasa Keuangan (OJK), GCG adalah ukuran kinerja OJK, selain itu juga ukuran kerja OJK adalah kinerja keuangan dan operasional. Dalam tata kelola OJK di Indonesia terbagi atas 4 bagian yaitu Governanve Principles, Governance Structure, Governance Process, dan Governance Outcome (Tentang OJK, www.ojk.go.id, Diakses 01 November 2019).

\section{a. Governance Principles}

Governance Principles memuat prinsip prinsip yang menjadi dasar pelaksanaan tata kelola yang baik. OJK telah mengupayakan penerapan GCG di seluruh proses fungsinyanya. Dalam implementasinya, Perusahaan mengacu kepada asas-asas Pedoman Umum GCG yang disebut TARIF, yaitu: Transparency (transparansi), Accountability (akuntabilitas), Responsibility (tanggung jawab), Independence (kemandirian), dan Fairness (kesetaraan dan kewajaran).

Transparency (transparansi), merupakan prinsip membukan diri terhadap hak pemangku kepentingan uentuk memperoleh inforrmasi yng beenar, jujur, dan tidak diiskriminatif, denngan tetap memperhaatikan hak asassi pribaadi dan golongan, termasuk rahasia sebagaimana ditetapkan dalam perundang-undangan. ${ }^{16}$ Untuk meningkatkan objektivitas dalam melakukan fungsinya, OJK selalu mengambil inisiatif untuk menyediakan dan mengungkapkan informasi material dan kebijakan terkait secara tepat waktu yang jelas, dapat diakses, dan dapat dipahami oleh semua pemegang saham, kreditor dan pemangku kepentingan lainnya. ${ }^{17}$ Maka, dengan adanya prinsip ini OJK akan terus menjaga rahasia lembaga sesuai dengan undang-undang dan peraturan, posisi dan kerahasiaan lembaga tanpa mengorbankan prinsip keterbukaan yang diperkenalkan sesuai dengan prinsip-prinsip Transparansi GCG. ${ }^{18}$

14 Agustina Melia, "Pengaruh Good Corporate Governance Terhadap Kinerja Perusahaan Pada Sektor Keuangan,” Business Accounting Review 3, no. 1 (2015): 223-32.

${ }^{15}$ Ahmad Fadli, "Penerapan Good Corporate Government (GCG) Pada Perbankan Syariah," Al-Mashraf 2, no. 1 (2016).

16 Aldira Maradita, "Karakteristik Good Corporate Governance Pada Bank Syariah Dan Bank Konvensional," Yuridika 29, no. 2 (2014).

17 Thomas S Kaihatu, “Good Corporate Governance Dan Penerapannya Di Indonesia,” Jurnal Manajemen Dan Kewirausahaan 8, no. 1 (2006): 1-9.

18 Tri Purwani, "Pengaruh Good Corporate Governance Terhadap Kinerja Perusahaan," Majalah Ilmiah Informatika 1, no. 2 (2010): 47-60. 
EKSPOSE: Jurnal Penelitian Hukum dan Pendidikan, 18 (2), Desember 2019 - 873

Nabilah Farah Diba, Hari Sutra Disemadi, Paramita Prananingtyas

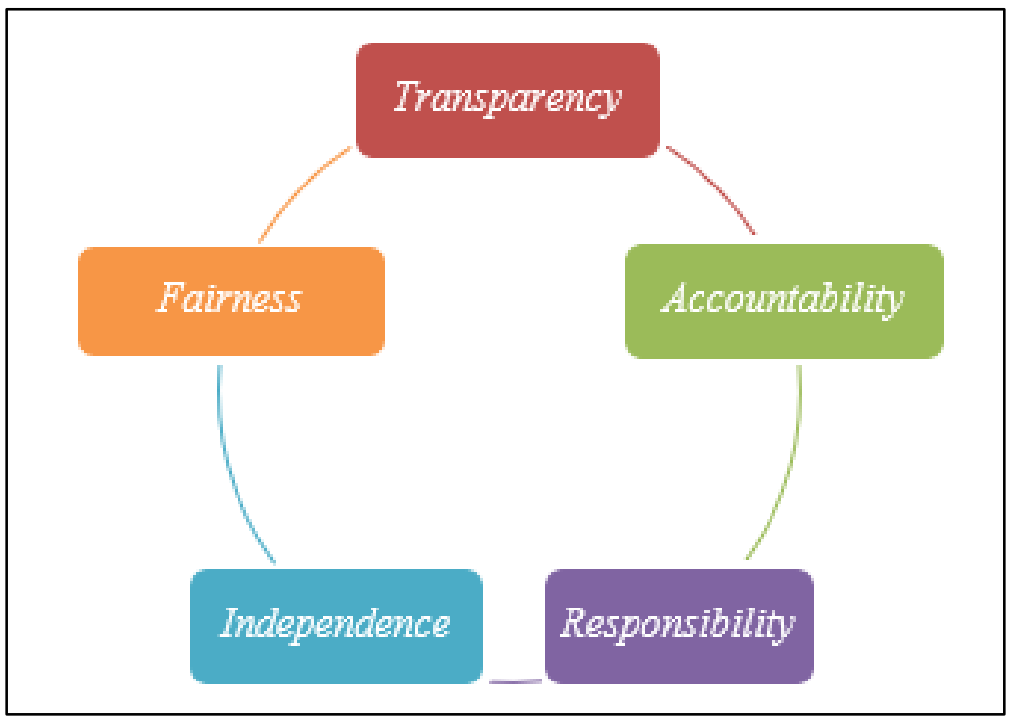

Gambar 1. Governance Principles

Accountability (akuntabilitas), adalah adalah prasyarat untuk kinerja yang baik dan berkelanjutan sehingga perusahaan dapat mengelola, mengukur, dan mengelola kepentingannya dengan benar, dengan selalu mempertimbangkan kepentingan pemegang saham dan pemangku kepentingan lainnya. ${ }^{19}$ Organ dan karyawan perusahaan harus selalu mematuhi etika dan kode perilaku perusahaan ketika menjalankan tanggung jawab dan kegiatan fungsi mereka. Prinsip ini mengedepankan kejelasan tugas, fungsi, wewenang dan tanggung jawa sehingga pengelolaan OJK berjalan dengan efektif.

Responsibility (pertanggungjawaban), dimaksudkan agar pengelolaan OJK sesuai dengan peraturan perundang-undangan, tersmasuk didalamnya budaya hukum. Sebagai bentuk pertanggungjawaban kepada masyarakat, epemrintah dan lingkungan, OJK selalu menerapkan prinsip kehati-hatian dan mematuhi peraturan OJK ketika melakukan salah satu kegiatannya. ${ }^{20}$

Independence (kemandirian), terkait bebebasan OJK selalu berusaha untuk menjalankan fungsinya secara independen dan satu pihak menghindari pelaksanaan kontrol, konflik kepentingan, dominasi satu entitas perusahaan di atas yang lain, dan tekanan atau pengaruh apa pun yang memengaruhi proses pengambilan keputusan. Diharapkan semua keputusan perusahaan akan lebih mandiri dan objektif. ${ }^{21}$ Artinya OJK memiliki kebebasan dalam mengambil keputusn dan pelaksanan fungsi, tuga, dan wewenag OJK, dengen tetap sesuai peraturan perundang-undangan yng berlaku. $^{22}$

Fairness (kesetaraan dan kewajaran), yaitu prinsip dalam memenuhi hak-hak dan perlakuan terhadap stakeholders. OJK selalu berusaha untuk memperlakukan kepentingan pemegang peran dan pihak ketiga yang berafiliasi dengan atau terkait dengan OJK sebagai adil dan adil, dan peluang yang sama bagi masyarakat terlepas dari kondisi fisik, ras, agama, ras, kelas dan jenis kelamin. ${ }^{23}$

b. Governace Structure

Struktur tata kelola OJK terdiri dari: 1). Organ utama tata kelola adalah Dewan Komisioner; yang berrsifat koleektif kolegial; 2). Orrgan peendukung tata kelola adelah Sekreteriat, Dewan Audit, Komite Etik dan komita leinnya; dan 3). Infraestruktur tata kelola tardiri dari pedoman (code), piagam (charter), paeraturan, prosedur (SOP) dan sisteem informassi sebagai acuan didalam menjalanken fungsi dan tugas, serta menarbitkan leaporan sebagai bentuk pertanggunngjawaban kepada pemangku kepentiingan.

${ }^{19}$ Fadli, "Penerapan Good Corporate Government (GCG) Pada Perbankan Syariah."

${ }^{20}$ Imam Mustofa, "Mengawal Prinsip-Prinsip Good Corporate Governance Dengan Penegakan Hukum," Jurnal Fakultas Hukum UII 7, no. 1 (2007): 181-94.

${ }^{21}$ Maradita, "Karakteristik Good Corporate Governance Pada Bank Syariah Dan Bank Konvensional."

${ }^{22}$ Melia, "Pengaruh Good Corporate Governance Terhadap Kinerja Perusahaan Pada Sektor Keuangan."

${ }^{23}$ Mustofa, "Mengawal Prinsip-Prinsip Good Corporate Governance Dengan Penegakan Hukum." 
EKSPOSE: Jurnal Penelitian Hukum dan Pendidikan, 18 (2), Desember 2019 - 874

Nabilah Farah Diba, Hari Sutra Disemadi, Paramita Prananingtyas

\section{c. Governance Process}

Pelaksananaan governance OJK didukung oleh fungsi asurans yang profesional dan obyektif dengan menggunakan model the three lines of defense (tiga lapis pertahanan) dan strategi combined assurance yang memberikan metode praktis untuk memastikan governance process di OJK berjalan secara efektif, yaitu: 1). The first line of defensee (perrtahanan lapis partama) dilaksanakan oleh Satuan Kerja yang melakukann aktivitas operasional seheri-hari, trutama yang merupekan garis depan attau ujung tombak OJK; 2). The second line of defense (pertahanan lapis kedua) dilaksanakan oleh Satuan Kerja Manajemen Risiko dan Pengendalian Kualitas yang bertanggung jawab untuk mengembangkan dan memantau implementasi manajemen risiko OJK secara keseluruhan sebagai bagian dari governance process; dan 3). The third line of defense (pertahanan lapis ketiga) dilaksanakan oleh Satuan Kerja Audit Internal beserta auditor eksternal yang bertanggung jawab untuk memastikan bahwa partahanan lapis peartama dan lapis kedua berjjalan sesuai denngan yang diharapkan.

Selain itu, OJK juga mengembangkan 3 (tiga ) inisiatif dalam rangka implementasi dan penguatan governance process, yaitu: 1). Pengendalian Gratifikasi; 2). Antti Fraud; dan 3). WBS (Whistle Blowing System).

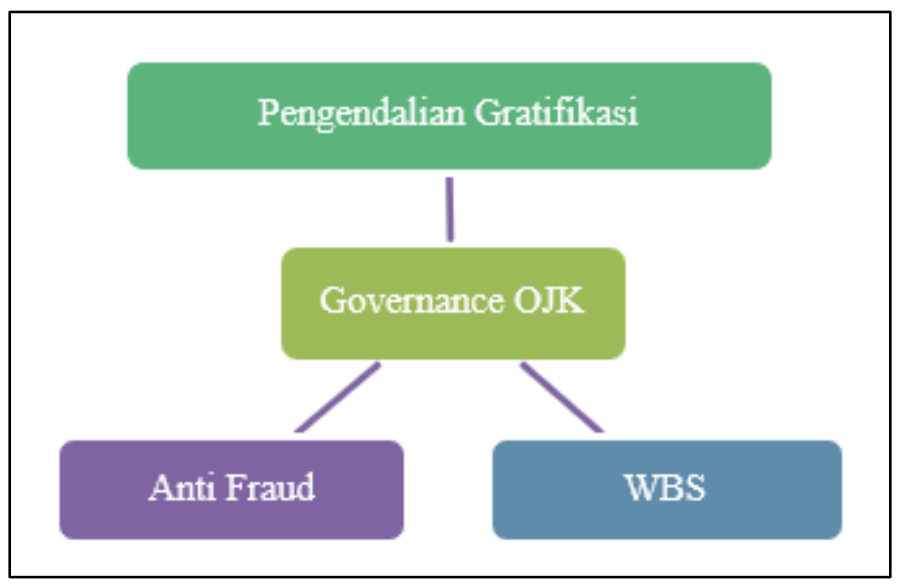

Gambar 2. Governance Process

Program Pengendalian Gratifikasi berfungsi mengendalikan Grattifikasi sebagaai pintu masuk korrupsi perlu dikendalikan; Program pengendallian grtifikasi adalah program nesional yng dikoordinasikan KPK; dan Memastikan penerapan code of conduct yang mengatur do's and dont's perilaku selurruh jajaran OJK. Kemudian revitallisasi Whistle Blowing System (WBS) bertujuan meningkatkan efektifitas pengelolaan pengaduan dan tindak lanjuttnya sarta optimalisesi penggunaan WBS OJK oleh stakeholder. ${ }^{24}$ Fungsi Anti Fraud OJK, bertujjuan untuk penyusunean strategi, edukaasi, penceegahan, deteksi, dan peninndakan fraud, kemudian koordinnasi pengendalian gratifikasi, monitoring, data analytic, dan penuntasan tindklanjut WBS.

\section{d. Governance Outcome}

Dengan prinisip, struktur dan proses governance yang dilaksanakan, OJK menetapkan Governance Roadmap pada Gambar 3.

Tujuan Perusahaan untuk menerapkan GCG ialah: 1). Mencapai tujuan OJK itu sendiri; 2). Mendorong pemberdayaan kemandirian, profesionalisme dan obyektivitas organ OJK dalam membuat keputusan dan dalam menjalankan tindakannya agar selalu dilandasi oleh transparansi, akuntabilitas, responsibilitas, independensi dan kesetaraan serta kewajaran dan prinsip kehati-hatian serta kepatuhan teerhadap peraturan dan perundang-undeagan yang berleaku; 3). Mendorong terciptanya hubungan dan lingkungan kerja yang baik, kondusif dan profesional di antara Organ OJK, masyarakat dan Pemerintah; dan 4). Menghindari adanya benturan kepentingan, penyelewengan, pernyataan palsu, pemberian suap dan diskriminasi.

${ }^{24}$ Sandi F S Rasjad, "Pengaturan Dan Pengawasan Otoritas Jasa Keuangan Terhadap Perbankan," Lex et Societatis 3, no. 3 (2015). 


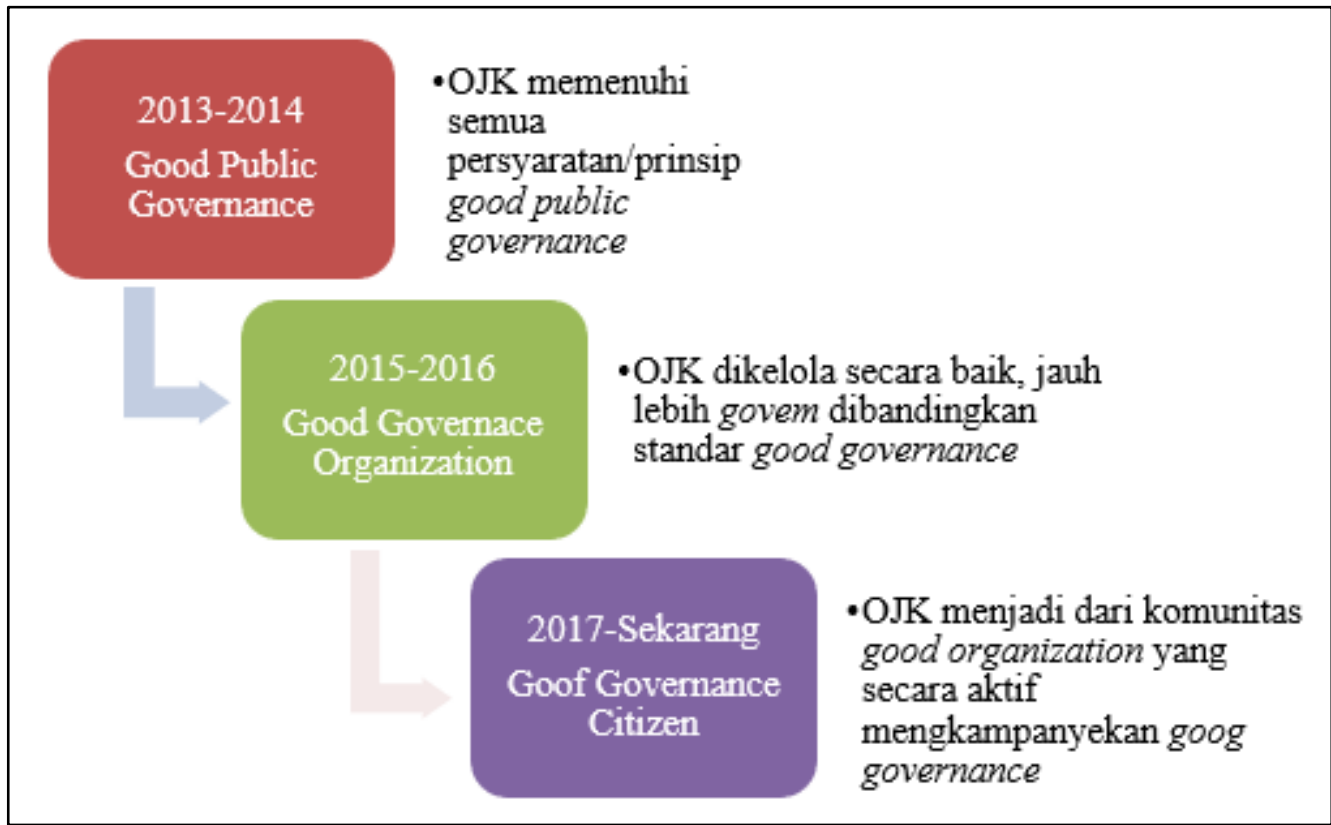

Gambar 3. Governance Roadmap

\section{SIMPULAN}

Negara Indonesia merupakan negara yang serius mengembangkan kegiatan jasa keuangan, berusaha menciptakan kerangka kerja hukum yang komprehensif serta dengan adanya pengaturan dan pengawasan sektor jasa keuangan. Banyaknya masalah lintas sektoral di sektor jasa keuangan, seperti ukuran risiko etika, perlindungan yang memadai terhadap konsumen jasa keuangan, dan stabilitas keuangan sektor jasa keuangan, membuat sektor jasa keuangan semakin dibutuhkan. Mengahruskan negara merestrukturisasi struktur kelembagaan perusahaan yang melakukan fungsi pengaturan dan pengawasan di sektor jasa keuangan, termasuk sektor perbankan, pasar modal, asuransi, dana pensiun, lembaga keuangan dan perusahaan jasa keuangan lainnya. Atas dasar hal ini hadirlah OJK atau Otoritas Jasa Keuangan. Pengaturan OJK di Indonesia terdapat dalam Undang-Undang Nomor 21 Tahun 2011 tentang Otoritas Jasa Keuangan (UU OJK).

UU OJK pada dasarnya berisi ketenntuan tentang organnisasi dan tata kelolla organisasi (Governace) dengan wewenang pengawasan dan peraturan di sektor jasa keuangan. OJK didirikan dengan tujuan mengelola semua kegiatan jasa keuangan dalam industri jasa keuangan secara sistematis, adil, transparan, dan bertanggung jawab dan mampu mewwujudkan sisteam keuangan yang berkembang secara beerkelanjutan, dan mammpu mellindungi kepentingan konssumen dan masyarakat. Sejalan dengan tujuan inii, tata kelola dalam pengelolaan OJK harus diperhatikan. Adapun tata kelola OJK terbagi atas 4 yakn Governanve Principles, Governance Structure, Governance Process, dan Governance Outcome. Tata kelola ini dimaksudkan untuk tercapainnya tujuan dari OJK itu sendiri.

\section{DAFTAR PUSTAKA}

Disemadi, Hari Sutra. "Risk Management In The Provision Of People's Business Credit As Implementation Of Prudential Principles." Diponegoro Law Review 4, no. 2 (2019): 194-208.

Disemadi, Hari Sutra, and Paramita Prananingtyas. "Perlindungan Hukum Terhadap Nasabah Perbankan Pengguna CRM (Cash Recycling Machine)." Jurnal Magister Hukum Udayana (Udayana Master Law Journal) 8, no. 3 (2019): 286-402.

Disemadi, Hari Sutra, and Kholis Roisah. "Kebijakan Model Bisnis Bank Wakaf Mikro Sebagai Solusi Pemberdayaan Ekonomi Masyarakat." LAW REFORM 15, no. 2 (n.d.): 177-94.

Disemadi, Hari Sutra, and Raden Ani Eko Wahyuni. "Eksistensi Dan Kebijakan Regulasi Perizinan Lembaga Keuangan Mikro Oleh Otoritas Jasa Keuangan.” Jurnal Yustisiabel 3, no. 2 (2019): 10617. 
Fadli, Ahmad. "Penerapan Good Corporate Government (GCG) Pada Perbankan Syariah." Al-Mashraf 2, no. 1 (2016).

Iskandar, Syamsu. "Bank Dan Lembaga Keuangan Lainnya.” Jakarta: In Media, 2013.

Kaihatu, Thomas S. “Good Corporate Governance Dan Penerapannya Di Indonesia.” Jurnal Manajemen Dan Kewirausahaan 8, no. 1 (2006): 1-9.

Lestari, HestyD. "Otoritas Jasa Keuangan: Sistem Baru Dalam Pengaturan Dan Pengawasan Sektor Jasa Keuangan.” Jurnal Dinamika Hukum 12, no. 3 (2012): 557-67.

Maradita, Aldira. "Karakteristik Good Corporate Governance Pada Bank Syariah Dan Bank Konvensional." Yuridika 29, no. 2 (2014).

Melia, Agustina. "Pengaruh Good Corporate Governance Terhadap Kinerja Perusahaan Pada Sektor Keuangan.” Business Accounting Review 3, no. 1 (2015): 223-32.

Mustofa, Imam. "Mengawal Prinsip-Prinsip Good Corporate Governance Dengan Penegakan Hukum." Jurnal Fakultas Hukum UII 7, no. 1 (2007): 181-94.

Purwani, Tri. "Pengaruh Good Corporate Governance Terhadap Kinerja Perusahaan.” Majalah Ilmiah Informatika 1, no. 2 (2010): 47-60.

Rasjad, Sandi F S. "Pengaturan Dan Pengawasan Otoritas Jasa Keuangan Terhadap Perbankan." Lex et Societatis 3, no. 3 (2015).

Samsul, Inosentius. "Perlindungan Konsumen Jasa Keuangan Pasca Pembentukan Otoritas Jasa Keuangan (OJK)." Negara Hukum: Membangun Hukum Untuk Keadilan Dan Kesejahteraan 4, no. 2 (2016): 153-66.

Sari, Shinta Puspita. "Pembentukan Pengaturan Tentang Good Corporate Governance (Gcg) Pada Bank Pembiayaan Rakyat Syariah." Legal Spirit 2, no. 1 (2018).

Sinaga, Rebekka Dosma, Bismar Nasution, and Mahmul Siregar. "Sistem Koordinasi Antara Bank Indonesia Dan Otoritas Jasa Keuangan Dalam Pengawasan Bank Setelah Lahirnya UndangUndang Nomor 21 Tahun 2011 Tentang Otoritas Jasa Keuangan.” TRANSPARENCY 1, no. 2 (2013).

Suteki, Taufani G. Metodologi Penelitian Hukum (Filsafat, Teori Dan Praktik). PT RajaGrafinfo Persada. Depok, 2018.

Yuliani, Yuliani. "Bank Dan Lembaga Keuangan Lainnya.” Citrabooks Indonesia, 2016.

Zaini, Zulfi Diane. "Hubungan Hukum Bank Indonesia Sebagai Bank Sentral Dengan Otoritas Jasa Keuangan (OJK) Pasca Pengalihan Fungsi Pengawasan Perbankan.” Media Hukum 20, no. 2 (2015) 